\title{
ANÁLISE MICROCLIMÁTICA EM FUNÇÃO DO USO E OCUPAÇÃO DO SOLO EM CUIABÁ-MT
}

\author{
microclimatic analysis as a function of land use in Cuiabá-MT, Brazil
}

Fernanda Miguel Franco*

Marta Cristina de Jesus Albuquerque Nogueira**

\begin{abstract}
Resumo
As cidades atualmente têm vivido as consequências das alterações climáticas que ocorrem como resultado de um desenvolvimento urbano pouco sustentável. O seguinte trabalho objetivou estudar o contexto climático urbano na cidade de Cuiabá-MT, para compreender as condições a nível microclimáticas do bairro do Porto. Realizou-se um levantamento qualitativo e quantitativo de acordo com a metodologia apresentada por Katzschner (1997). Foram coletados dados de umidade relativa e temperatura do ar nas quatro estações do ano, três vezes ao dia $(8 \mathrm{~h}, 14 \mathrm{~h}$ e $20 \mathrm{~h})$, utilizando o método do transecto móvel. Observou-se com a pesquisa que locais com uso de solo e área construída semelhante tendem a ter as mesmas características de umidade relativa e temperatura do ar. Os processos de diversificação do microclima ocorridos nas cidades não dependem apenas da distribuição da malha urbana, mas também do funcionamento da vida citadina, como foi observado no estudo realizado.
\end{abstract}

Palavras-chave: Clima urbano, Conforto ambiental, Bioclimatologia.

\begin{abstract}
Cities have experienced the consequences of climate change that occur as a result of urban development not sustainable. The study investigated the climatic context in the city of Cuiaba, to understand the microclimate conditions at the neighborhood of Porto. We conducted a qualitative and quantitative survey in accordance with the methodology used by Katzschner (1997). We collected data on relative humidity and air temperature in four seasons of the year, three times a day ( 8 a.m., 2 p.m. and 8 p.m.), using the method of mobile transect. It was observed that with the research with local land use and building area tend to have similar characteristics to the same relative humidity and air temperature. The processes of diversification of microclimate in cities not only depend on the distribution of the urban fabric, but also the functioning of city life, as observed in the study.
\end{abstract}

Key words: Urban climate, Environmental comfort, Bioclimatology.

\section{Résumé}

Les villes subissent les conséquences des changements climatiques qui se produisent en raison d'un développement urbain non durable. La recherche suivante étudie le contexte climatique de milieu urbain dans la ville de Cuiaba-MT, pour comprendre les conditions microclimatiques du district de Porto. Nous avons mené une enquête qualitative et quantitative selon la méthodologie présentée par Katzschner (1997). Nous avons recueilli des données sur l'humidité relative et température de l'air en quatre saisons, trois fois par jour ( $8 \mathrm{~h}, 14 \mathrm{~h}$ et $20 \mathrm{~h}$ ) en utilisant la méthode des transects mobile. On a observé que la recherche utilisation des terres urbaines et de la zone de construction ont tendance à avoir des caractéristiques semblables de humidité relative et la température de l'air. Les processus du microclimat de la ville dépend pas seulement de la répartition du tissu urbain, mais aussi le fonctionnement de la vie en ville, comme on l'observe dans l'étude.

Mots-clés: Climat urbain, Confort enviromental, Bioclimatologie.

(*) Doutoranda do Programa de Pós-Graduação em Física Ambiental da Universidade Federal de Mato Grosso - Av. Fernando Corrêa da Costa, s/nº, CEP: 78.060-900, Cuiabá (MT), Brasil., Tel.: (+55 65) 36158738 - fermifran@yahoo.com.br

(**) Bolsista Produtividade do CNPq. eProf ${ }^{a}$. Dr ${ }^{\mathrm{a}}$. do Programa de Pós-Graduação em Física Ambiental da Universidade Federal de Mato Grosso - Av. Fernando Corrêa da Costa, s/nº, CEP: 78.060-900, Cuiabá (MT), Brasil, Tel.: (+55 65) 36158738 - mcjanp@gmail.com 


\section{INTRODUÇÃO}

O estudo do clima urbano possui uma perspectiva multidirecional, sendo assim de grande interesse as modificações causadas pela ação antrópica. O maior desafio das grandes cidades é a busca por um desenvolvimento urbano que proporcione a geração de riqueza, qualidade de vida e ambiental para seus atuais e futuros habitantes.

Oke (1987) afirma que há características particulares no meio ambiente urbano, como rugosidade, ocupação do solo, orientação, propriedades termodinâmicas dos materiais, entre outros fatores que modificam as suas feições climáticas, formando um clima particular.

As interferências humanas na paisagem natural vêm causando mudanças significativas no microclima de cada região. Essas alterações se repetem em todas as grandes cidades, sendo caracterizadas pelo aumento da temperatura do ar e diminuição da umidade relativa, causados principalmente pela ausência de áreas verdes, pela presença de concreto e asfalto, pela construção de prédios que impedem a ventilação natural, pelo aumento da atividade industrial e da poluição proveniente dos veículos automotores.

Assim a preocupação com a qualidade ambiental urbana, deve estar inserida em todo processo de urbanização, seja ele acelerado ou não, considerando assim o estudo da climatologia urbana um instrumento importante no processo de planejamento das cidades, como também, na busca de estratégias de amenização de problemas climáticos urbanos já existentes. Para Katzschner (1997), os fenômenos urbanos são, até certo ponto, reversíveis, ou seja, pode ser alterados ou controlados pelas ações de planejamento, desenho urbano e projeto de edifícios, pode-se até restaurar ou amenizar as condições ambientais indesejadas.

A cidade de Cuiabá surgiu da exploração do ouro pelos bandeirantes, e tinha como cenário urbanístico um traçado simples desenvolvido às margens do córrego da Praínha. Possuindo ainda características de relevo que impedem uma boa formação de ventos, céu claro na maior parte do ano e clima quente.

O estudo climático urbano em Cuiabá é fundamental para uma maior compreensão dos impactos da ação do homem sobre a cidade, e também para a identificação das falhas e acertos da ocupação humana, deste modo é necessário reunir informações sobre as características climáticas do local e a partir daí compreender o comportamento das escolhas urbanísticas existentes, avaliando seu desempenho térmico.

Nos últimos vinte anos, Cuiabá vem apresentando um acelerado crescimento demográfico juntamente com uma expansão da malha urbana. Esse crescimento nem sempre vem aliado a um planejamento urbano adequado, sendo, na maioria dos casos direcionado pelas vontades do setor imobiliário, que não leva em consideração as questões ambientais.

A cidade apresenta altas temperaturas do ar ao longo de todo ano, resultando em desconforto térmico na maioria de seus habitantes expostos às condições climáticas dos espaços abertos. Dentro deste contexto citadino, o estudo da influência da configuração urbana no microclima, poderia levar a identificação de estratégias para amenizar as altas temperaturas locais.

O bairro do Porto surgiu juntamente com a colonização da cidade de Cuiabá, no século XVII, possuindo um misto de atividades comerciais e residenciais, característica ainda observada atualmente. A escolha do bairro em questão deveu-se pela sua importância histórica e também devido a sua proximidade com o rio Cuiabá, havendo uma grande área verde ainda preservada.

O objetivo do estudo foi realizar um levantamento quantitativo e qualitativo das condições climáticas do Bairro do Porto, identificando a importância do desenvolvimento da malha urbana, assim como a influência da ação antrópica nas características higrotérmicas desse bairro, além disso, buscou-se avaliar a influência da proximidade com o rio Cuiabá, e as áreas verdes no comportamento microclimático local.

O planejamento urbano deve ser um projeto bioclimático que envolve o clima, o homem e o habitat, num processo de otimização, entre o meio no qual se projeta, o habitante e a própria 
edificação, é dever do gestor buscar, portanto, as condições favoráveis do clima, com a intenção de satisfazer às exigências de conforto térmico do homem (OLGYAY, 1963).

\section{METODOLOGIA}

Estudos sobre clima urbano buscam sempre a verificação de como os homens interferem no meio em que estão inseridos. As cidades são exemplo de como essas transformações antrópicas se tornan por vezes invasivas, mudando completamente a paisagem natural.

\section{Área de estudo}

O Centro Oeste brasileiro tem clima caracterizado por invernos secos e verões chuvosos. $\mathrm{O}$ tempo seco no inverno tem sua origem na estabilidade gerada pela influência do anticiclone subtropical do Atlântico Sul e de pequenas dorsais que se formam sobre o continente (NIMER, 1989).

A cidade de Cuiabá situa-se no centro geodésico da América do Sul, localizada nas coordenadas geográficas, $15^{\circ} 35^{\prime} 56^{\prime \prime}$ latitude Sul e $56^{\circ} 06^{\prime} 01^{\prime}$ " longitude Oeste. É uma cidade pertencente à região centro-oeste do Brasil mais precisamente no estado do Mato Grosso. Situa-se na província geomorfológica denominada Depressão Cuiabana.

De acordo com dados do INMET a cidade possui pequena amplitude térmica, exceto em fenômenos de friagem, temperatura média anual de $26,8^{\circ} \mathrm{C}$, com média das máximas de $42^{\circ} \mathrm{C}$ e médias das mínimas de $15^{\circ} \mathrm{C}$ e insolação total média de 2.179 horas. A direção predominante dos ventos é N e NO durante boa parte do ano e S no período de inverno. Na classificação de KÖPEN podemos observar praticamente as mesmas características, sendo o clima de Cuiabá do tipo Aw, isto é, tropical semiúmido.

Quadro 1 - Temperaturas médias mensais dos anos de 1990 a 2004

\begin{tabular}{|c|c|c|c|c|c|c|c|c|c|c|c|c|}
\hline$A N O$ & AN & FEV & MAR & BR & & & & & & & & \\
\hline 1990 & 26,80 & 26,50 & 27,20 & 26,60 & 24,20 & 3,70 & 1,50 & 25,30 & 24,80 & 8,20 & 7,20 & 7,20 \\
\hline 1991 & 7,20 & 27,20 & 6,20 & 26,30 & 25,70 & 24,00 & 2,80 & 24,50 & 27,50 & 27,10 & 7,50 & 7,60 \\
\hline 1992 &, 90 & 26,70 &, 70 &, 50 &, 10 & 5,00 & 1,20 & 1,40 & 24,80 & 6,90 & 6,60 & 7,3 \\
\hline 1993 & 20 & 5,90 & 60 & 26,90 & 1,70 & 30 & 2,20 & 3,60 & 27,30 & 3,30 & 8,30 & 1,00 \\
\hline 1994 & 30 & 26,80 & 7,10 & 26,60 & 80 & 4,00 & 2,80 & 1,80 & 27,50 & 60 & 40 & 3,70 \\
\hline 1995 & 26,80 & 26,70 & 27,10 & 25,70 & 24,60 & 23,70 & 4,40 & 5,30 & 27,10 & 28,00 & 7,50 & 26,50 \\
\hline 1996 & 26,30 & 27,00 & 7,10 & 26,70 & 25,30 & 21,10 & 23,20 & 27,30 & 26,60 & 27,00 & 27,00 & 27,90 \\
\hline 1997 & 26,50 & 26,60 & 26,90 & 25,90 & 24,40 & 24,40 & 24,50 & 25,10 & 27,10 & 29,10 & 28,90 & 27,90 \\
\hline 1998 & 28,50 & 27,80 & 7,90 & 27,30 & 24,30 & 23,50 & 4,90 & 26,10 & 21,90 & 28,10 & 27,50 & 27,20 \\
\hline 1999 & 27,10 & 27,30 & 26,20 & 26,20 & 24,70 & 23,70 & 3,40 & 24,70 & 28,00 & 28,70 & 27,00 & 27,50 \\
\hline 2000 & 28,30 & 27,00 & 26,70 & 26,50 & 25,80 & 24,50 & 22,80 & 27,50 & 26,40 & 28,30 & 27,50 & 27,30 \\
\hline 2001 & 27,00 & 27,30 & 26,60 & 27,20 & 25,10 & 22,00 & 24,80 & 26,70 & 27,80 & 27,60 & 27,10 & 26,30 \\
\hline 2002 & 26,90 & 26,50 & 26,10 & 27,00 & 24,90 & 23,00 & 24,20 & 26,80 & 27,30 & 29,40 & 28,70 & 28,00 \\
\hline 2003 & 26,90 & 25,40 & 26,30 & 25,90 & 24,70 & 24,20 & 23,00 & 24,50 & 27,10 & 27,40 & 26,50 & 28,00 \\
\hline 2004 & 27,20 & 27,40 & 7,70 & 27,00 & 23,20 & 23,90 & 23,40 & 25,20 & 27,20 & 28,20 & 27,10 & 27,90 \\
\hline \multirow[t]{2}{*}{ MÉDIAS } & 26,98 & 26,55 & 26,74 & 26,54 & 25,00 & 23,48 & 23,16 & 25,10 & 26,26 & 27,86 & 27,41 & 27,21 \\
\hline & $3^{\circ}+Q$ & $6^{\circ}+F$ & $6^{\circ}+Q$ & $5^{\circ}+F$ & $3^{\circ}+F$ & $2^{\circ}+F$ & $1^{\circ}+F$ & $4^{\circ}+F$ & $5^{\circ}+Q$ & $1^{0}+Q$ & $2^{\circ}+Q$ & $4^{\circ}+Q$ \\
\hline
\end{tabular}

FONTE: LEÃO, 2007

O Bairro do Porto constitui-se em um dos pontos mais antigos de Cuiabá. Após a descoberta das Lavras do Sutil (1722), ocorreu uma expressiva migração dos primeiros povoadores, fixados inicialmente na região do Coxipó-Mirin, para as margens do Córrego da Prainha, (SIQUEIRA et al, 2007). O Bairro fica localizado na região Oeste com uma área de 248,22 ha e população de 9.335 pessoas. 


\section{Materiais utilizados na coleta de dados}

Para a coleta de dados no transecto móvel, foi utilizado o Termo-higro-anemômetro digital portátil, Modelo THAR - $185 \mathrm{H}$ da marca Instrutherm. Construiu-se um abrigo para proteger o Termo-higro-anemômetro da radiação solar direta e precipitação durante a coleta de dados no transecto móvel.

\section{Período e frequência de coleta de dados}

Os dados foram coletados durante os períodos correspondentes as estações do ano, verão, no período de 04 a 13 de Fevereiro de 2009, outono, no período de 04 a 13 de junho de 2009, inverno, no período de 23 de julho a 1 de agosto de 2009 e primavera, no período de 08 a 17 de outubro.

As medições do transecto móvel foram realizadas em três períodos distintos ( $8 \mathrm{~h}, 14 \mathrm{~h}$ e $20 \mathrm{~h}$ ) em um percurso composto por 24 pontos (figura 1) durante 10 dias em cada estação. Estes horários foram estabelecidos de acordo com os horários (8,14 e 20 horas) utilizados para a coleta de dados na estação meteorológica do INMET em Cuiabá-MT. Segundo Maitelli (1994) o método do transecto móvel permite avaliar melhor o comportamento térmico e higrométrico em um espaço maior dentro do contexto urbano.

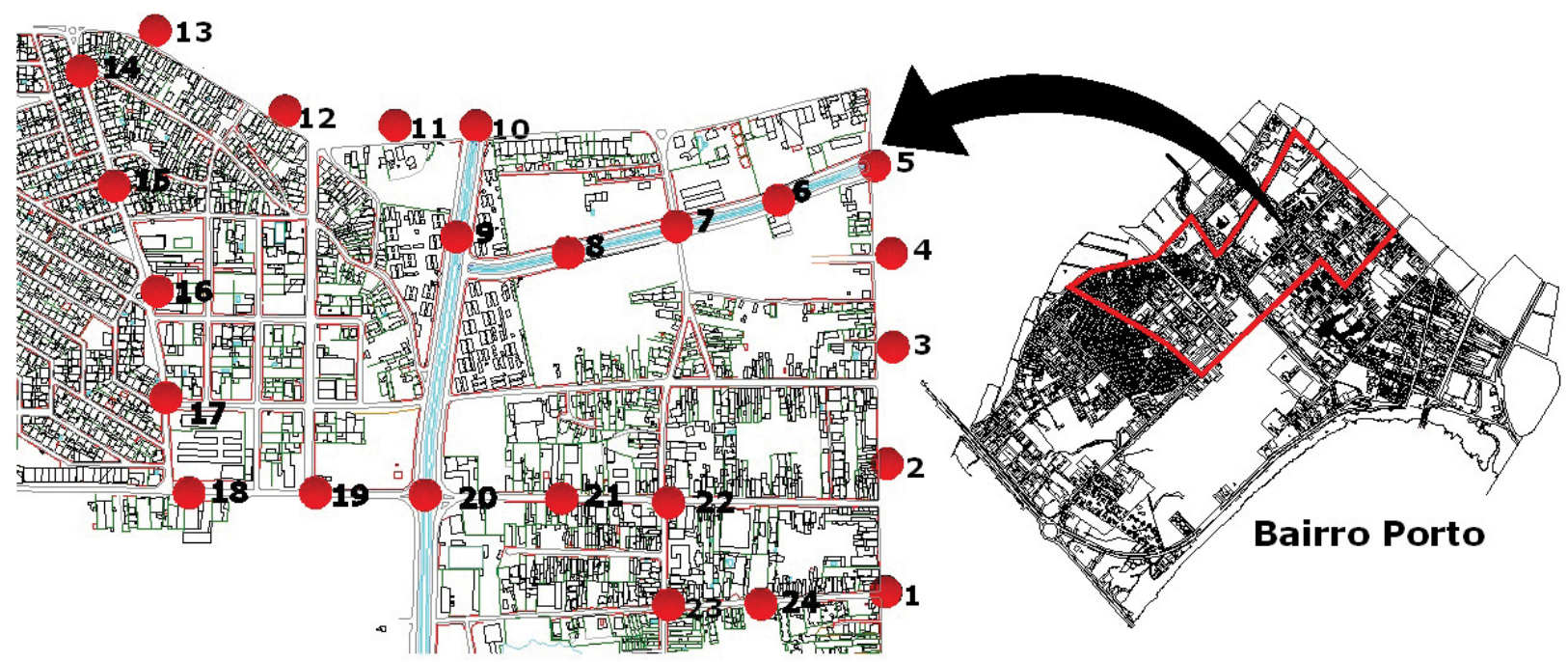

Trajeto Transecto

Figura 1 - Percurso do transecto móvel Fonte: Franco (2010)

\section{Metodologia da coleta de dados}

Adotou-se como referencial teórico-metodologico Katzschner (1997), sendo assim, foi definido um método que analisa as condições do clima urbano através de descrições qualiquantitativas do ambiente. O procedimento adotou a seguinte ordem (elaboração de mapas, análise qualitativa dos mapas, definição dos pontos de medida, medição das variáveis ambientais e análise quantitativa comparativa dos dados). Foram elaborados quatro mapas distintos (área edificada, uso e ocupação do solo, áreas verdes e altura das edificações), a partir das características urbanas foram escolhidos os pontos de medida das variáveis ambientais (temperatura do ar e umiade relativa). Por último, com os dados já coletados, foi realizada uma análise hierárquica de agrupamantos e um dendrograma de similaridade para a avaliação dos dados e seu comportamento segundo as características urbanas. 


\section{RESULTADOS E DISCUSSÕES}

\section{Mapas de caracterização do bairro Porto}

A caracterização qualitativa da área de estudo, se faz necessária devido a sua importância na variação microclimática dentro do contexto urbano. Tendo em vista esta preocupação, foram confeccionados mapas contendo alguns aspectos importantes na classificação do espaço citadino.

A área edificada ocupa um total de $513.810,5499 \mathrm{~m}^{2}$, o que representa $19,86 \%$ do total da área do bairro (figura 2A), não incluindo a área de pavimentação das vias. A determinação dessa área, de forma indireta, nos permite saber o nivel de permeabilidade do solo do bairro, assim como a capacidade de escoamento das águas pluviais. A porcentagem de área ocupada por edificações também nos remete a outro problema da urbanização, que são os materiais empregados nas construções e sua relação com a elevação dos niveis de temperatura do ar devido à refletância. Givone (1989) afirma que a densidade de área construída resulta de características independentes do desenho urbano, como por exemplo, as taxas de ocupação da área construída, distâncias entre edificações e alturas médias dos edifícios.

A verticalidade urbana (figura 2B) exerce grande influência no microclima local, pois a altura das edificações tem a propriedade de modificar ou até impedir a circulação de ar, além de alterar a parcela de visão do céu, sombreando ou servindo como corpo refletor. Para o clima de Cuiabá é apropriado que se considere o fator sombreamento como positivo, já que a exposição solar aumenta a temperatura do ar. O Sombreamento por área construída, elementos (pérgulas, quiosques ou marquises) ou pela disposição das árvores, juntamente com o uso de materiais de superfície com baixa absorção e reflexão, podem minimizar os problemas provocados pelo excesso de radiação solar. (CORBELLA \& MAGALHÃES, 2008)

A altura dos edifícios em relação à largura da rua deve permitir que a luz do sol atingisse a rua no meio da manhã, de forma a dissipar as inversões térmicas locais no nível da rua e permitir a penetração das brisas para dispersarem e diluírem os poluentes. (SPIRN, 1995)

O uso e ocupação do solo (figura 2C) também é responsável pelas modificações microclimáticas. Certas atividades humanas contribuem para um aumento do trânsito de veículos automotores, aumento da emissão de gases na atmosfera e consequentemente aumento de temperatura do ar. O uso de aparelhos de ar condicionado, segundo Sailor (2006), pode aumentar a temperatura do ar nas proximidades do equipamento, já que há emissão de calor para a atmosfera. Sendo assim, as atividades institucionais e comerciais identificadas no bairro do Porto provocam impactos sobre as condições climáticas locais.

De acordo com Monteiro e Mendonça (2003) a materialidade física da cidade e as atividades dela decorrentes promovem alterações nos balanços energético, térmico e hídrico, trazendo como efeito modificações importantes nas propriedades físicas e químicas da atmosfera, propiciando, a criação de condições climáticas distintas de áreas não urbanizadas.

As áreas verdes existentes no Bairro Porto ocupam uma área de $960.993,8236 \mathrm{~m}^{2}$, representada por $37,15 \%$ da área total do bairro (figura 2D). Sendo assim as áreas verdes se sobrepõe as áreas edificadas. Foram próximas as áreas verdes que se obtiveram as menores temperaturas do ar, e as maiores taxas de umidade relativa. De acordo com Katzschner (1997), as áreas verdes das cidades devem ser mantidas livres, para induzir os sistemas de circulação térmica conduzindo a efeitos bioclimáticos positivos.

Em Atenas na Grécia Tsiros (2010) observou em medições de temperatura do ar sob o dossel da vegetação urbana, que a média do efeito do resfriamento no período das $14 \mathrm{~h}$, foi encontrada na faixa de $0,5^{\circ} \mathrm{C}$ a $1,6^{\circ} \mathrm{C}$ e às $17 \mathrm{~h}$ de $0,4^{\circ} \mathrm{C}$ a $2,2^{\circ} \mathrm{C}$. Estes resultados indicam o potencial de resfriamento passivo da sombra das árvores. 
FRANCO. F. M.; NOGUEIRA, M. C. J. A.

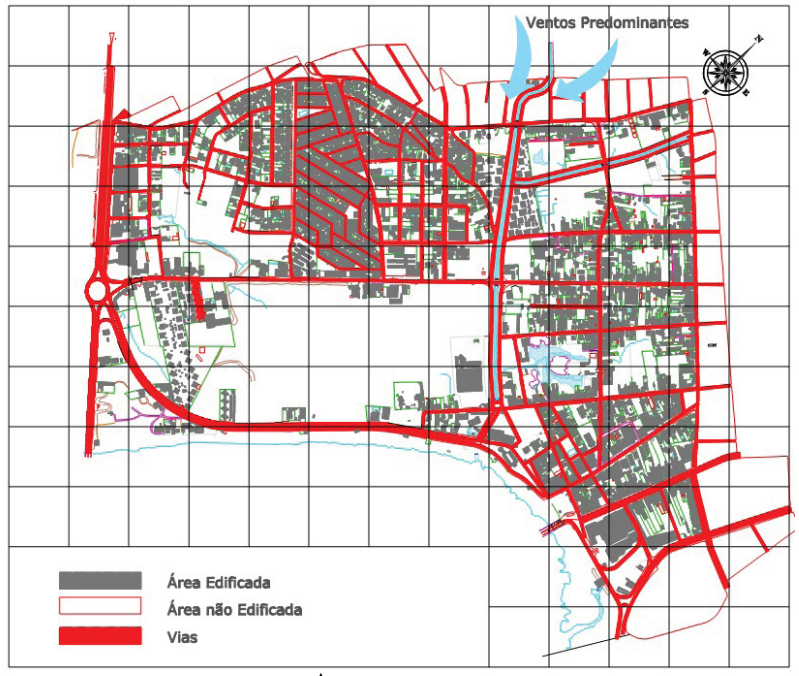

A

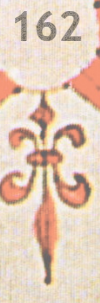

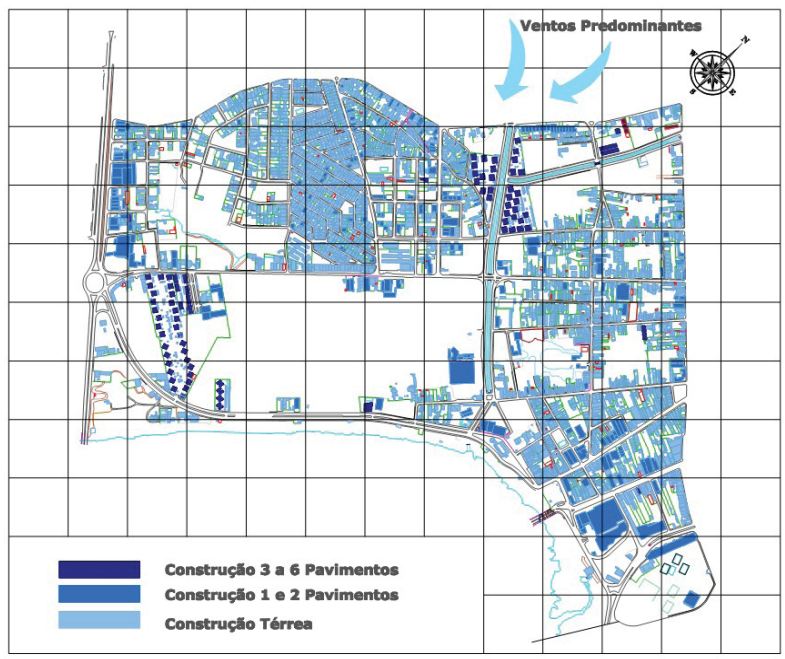

B

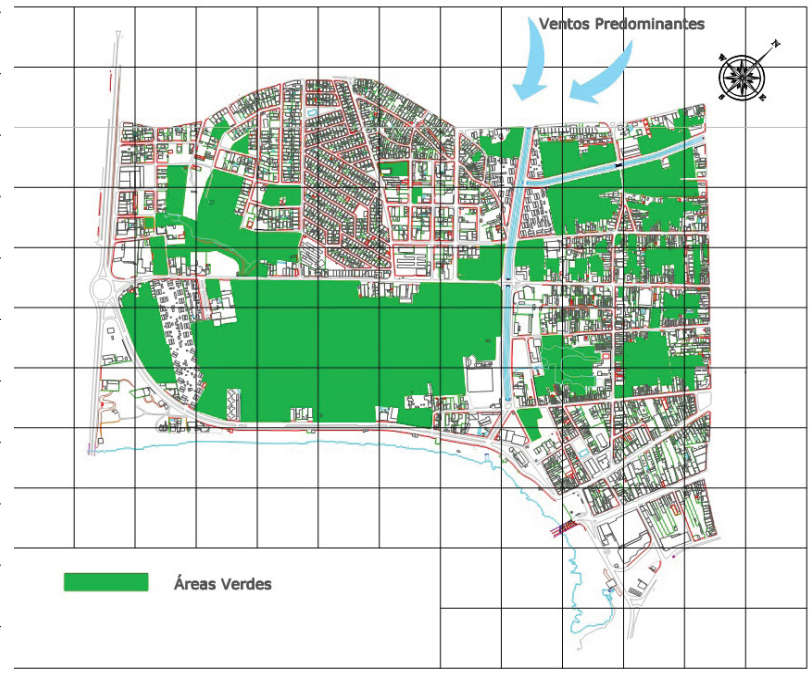

D

Figura 2 - Mapas de área edificada A, altura das edificações B, uso e ocupação do solo C e áreas verdes D, a escala da malha é de $200 \times 200$. 
Frischenbruder e Pellegrino (2006) afirmam que o planejamento do espaço aberto no Brasil e a existência dos espaços verdes nas áreas urbanas são acontecimentos muito recentes, principalmente, porque poucas cidades foram o resultado de ações planejadas ao longo do tempo. No caso do bairro Porto, há uma concentração verde que não deve ser desprezada e de acordo com os resultados da pesquisa traz resultados benéficos ao microclima local.

Análise qualitativa (verão, outono, inverno e primavera)

Na comparação do comportamento das temperaturas médias da manhã (figura 3) nos pontos do transecto, foram observadas as maiores temperaturas do ar na estação da primavera, com médias de aproximadamente $31^{\circ} \mathrm{C}$, seguidas pelas encontradas na estação do verão, com médias de $25^{\circ} \mathrm{C}$, enquanto nas estações de outono e inverno observa-se um comportamento semelhante, no entanto com menores temperaturas, em média $23^{\circ} \mathrm{C}$. Oposta ao comportamento da temperatura do ar a umidade relativa (figura 4 ) da primavera foi a menor $(51 \%)$ encontrada nos pontos do transecto. No verão observou-se a maior umidade relativa média (74\%), seguida pela estação do outono e do inverno $73 \%$ e $66 \%$ respectivamente.

As maiores temperaturas médias do ar (Figura 3) encontradas no período matutino foram nos pontos, 1 (verão $25,1^{\circ} \mathrm{C}$ e outono $21,5^{\circ} \mathrm{C}$ ), 20 (inverno $21,6^{\circ} \mathrm{C}$ ) e 23 (primavera $32^{\circ} \mathrm{C}$ ). Nos pontos descritos pôde-se verificar a influência do trânsito de veículos automotores e do tipo de atividade exercida, considerando que estão em regiões distintas dentro da malha urbana. A reduzida taxa de área construída, proximidade com áreas verdes e curso d'água não tiveram grande influência como amenizador térmico no caso do ponto 20 no período matutino.

As menores temperaturas médias do ar (Figura 3) foram obtidas nos pontos 6 (verão $24,4^{\circ} \mathrm{C}$ ), 8 (outono $20,8^{\circ} \mathrm{C}$ e inverno $20,6^{\circ} \mathrm{C}$ ) e 3 (primavera $30,8^{\circ} \mathrm{C}$ ). Os três pontos encontram-se, próximos dentro da malha urbana, sendo que os pontos 6 e 8 estão na mesma via com presença de área verde, área não edificada e curso d'água, e o ponto 3 está locado próximo a uma árvore de grande porte e relativamente próximo aos outros dois pontos.

Como fator amenizador climático no caso acima se pôde considerar a presença de vegetação e água. Xu et al. (2010) confirma a presença de água na malha urbana como importante fator amenizador climático.

As maiores umidades relativas médias do ar (Figura 4) foram aferidas nos pontos 8 (verão 77,3\%), 20 (outono 75,7), 19 (inverno 68,1\%) e 7 (primavera 52,6\%). É notado em todos os casos a presença de áreas verdes, embora estejam em regiões distintas dentro do bairro. As menores umidades relativas médias foram observadas nos pontos 2 (verão 74,8\%), 1 (outono 71,3\% e inverno 63,3\%) e 19 (primavera 50,7\%), os pontos estão localizados em via de elevado tráfego de veículos. As características da malha urbana dos pontos 1 e 2 são distintas do ponto 19 que fica próximo a uma grande área verde, sendo assim a emissão de $\mathrm{CO}^{2}$ pelos veículos foi responsável direta pela diminuição da umidade relativa do ar. 


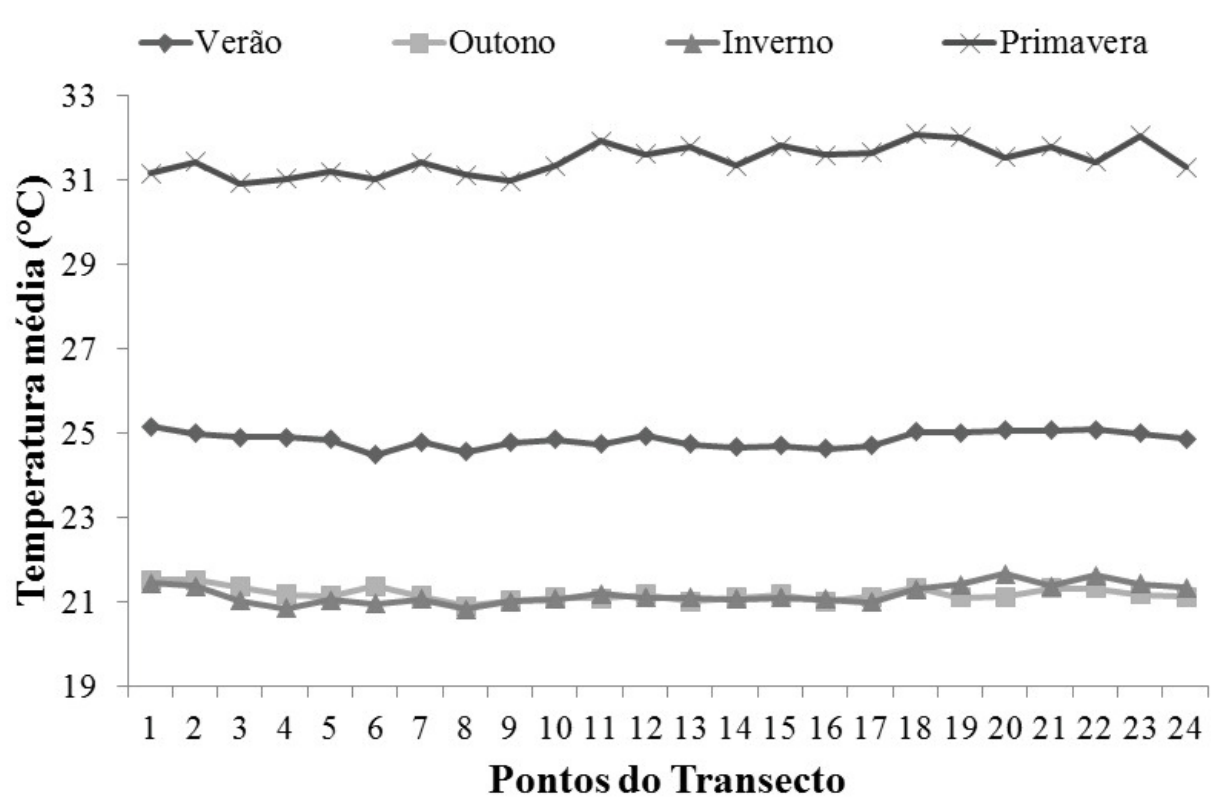

Figura 3 - Valores das temperaturas do ar nos 24 pontos do transecto nas quatro estações do ano (verão, outono, inverno e primavera) período matutino $(8 \mathrm{~h})$

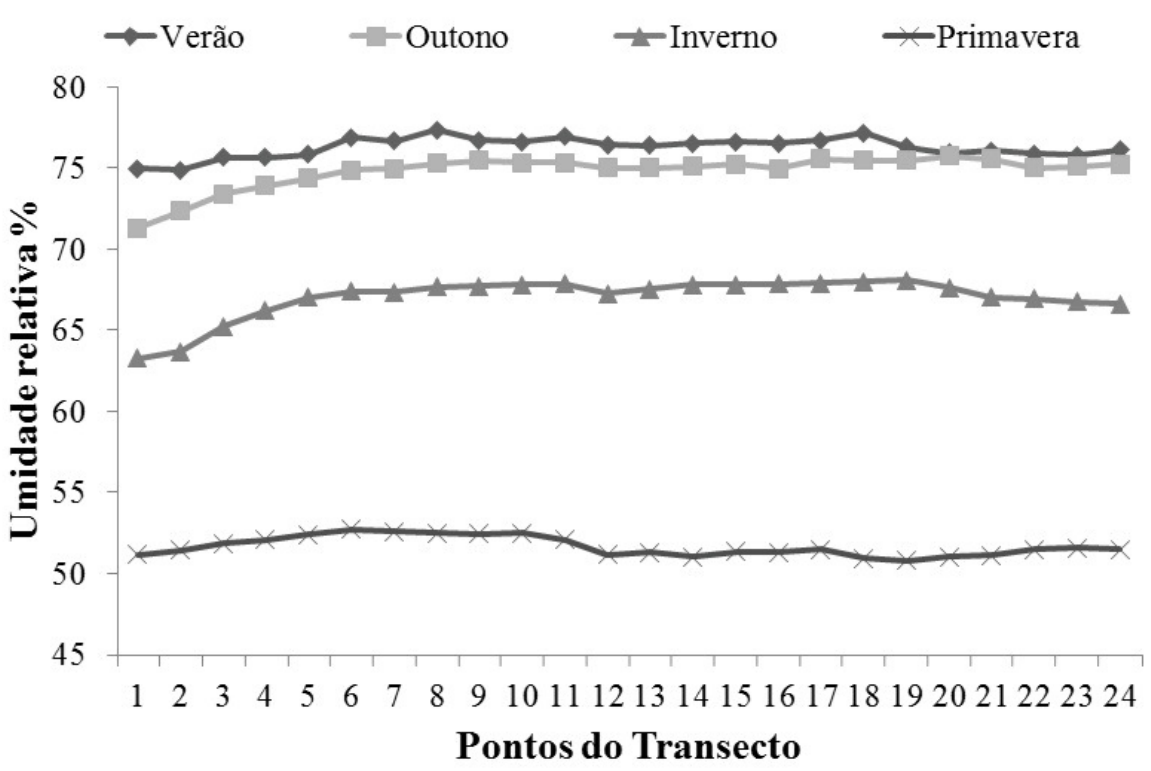

Figura 4 - Valores das umidades relativas nos 24 pontos do transecto nas quatro estações do ano (verão, outono, inverno e primavera) período matutino $(8 \mathrm{~h})$

No comportamento das temperaturas médias da tarde (figura 5), como no período matutino, observaram-se na primavera as maiores temperaturas do ar aproximadamente $36^{\circ} \mathrm{C}$ seguidas pelas encontradas na estação do verão $33^{\circ} \mathrm{C}$, do outono $30^{\circ} \mathrm{C}$ e do inverno $27^{\circ} \mathrm{C}$, no qual foram aferidas as menores temperaturas médias. A umidade relativa média do ar da primavera $37 \%$ foi a menor encontrada nos pontos do transecto, o inverno obteve a maior umidade relativa média $53 \%$, seguido pelo verão $52 \%$ e o outono $49 \%$ (figura 6 ).

$\mathrm{Na}$ figura 5 observa-se que as maiores temperaturas médias do ar encontradas no período vespertino foram nos pontos 1 (verão $33,8^{\circ} \mathrm{C}$ ), 2 (outono $30,4^{\circ} \mathrm{C}$ e inverno $27,5^{\circ} \mathrm{C}$ ) e 11 (primavera $36,9^{\circ} \mathrm{C}$ ). No caso dos pontos 1 e 2 , estão localizados em regiões próximas dentro da malha urbana, já o ponto 11 está afastado, mas tem características em comum com os dois primeiros como a presença de comércios, a intensidade do tráfego de veículos e a área construída. Foi observado que a atividade humana foi a principal responsável pela alta da temperatura. Oliveira (1993), afirma que 
quanto maior a concentração de usos, isto é, elementos contendo atividades industriais, comerciais e de prestação de serviços, maior será a transmissão de calor e de poluentes para a atmosfera e, conseqüentemente, maiores serão as modificações ocasionadas no clima, enquanto que parques e áreas com único uso apontam para menores alterações no clima.

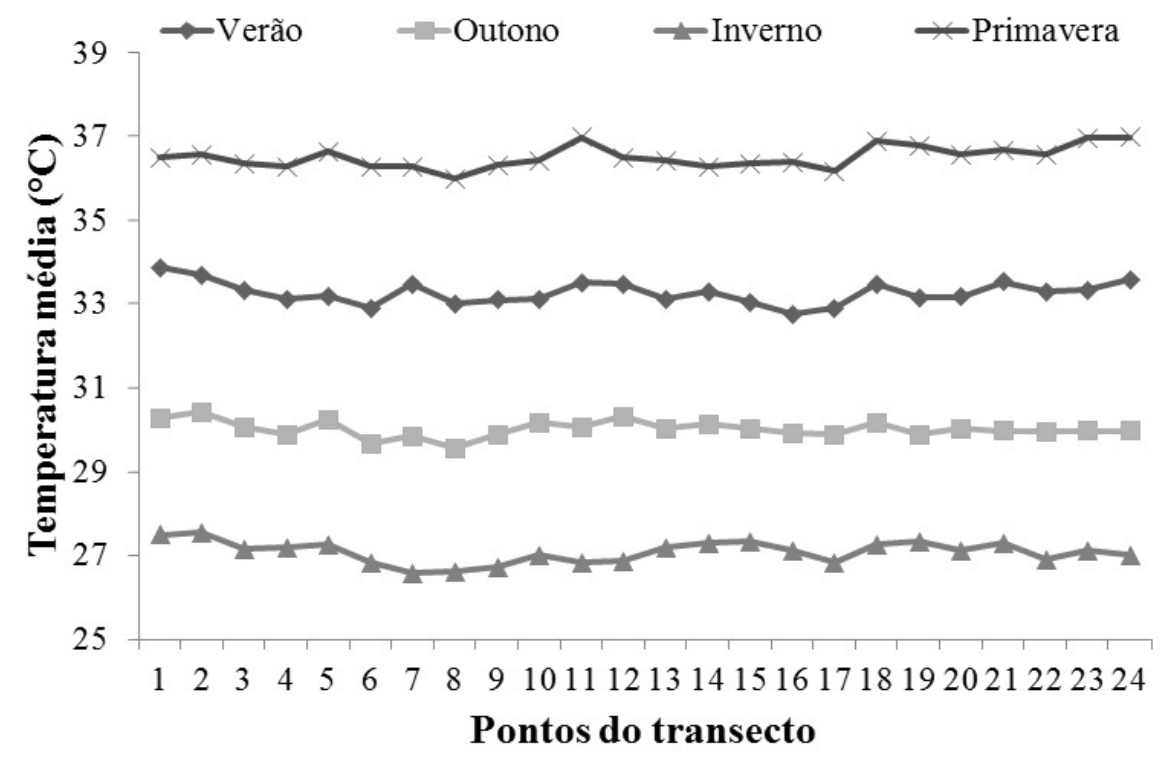

Figura 5 - Valores das temperaturas do ar nos 24 pontos do transecto nas quatro estações do ano (verão, outono, inverno e primavera) período vespertino (14h).

As menores temperaturas médias do ar (Figura 5) foram obtidas nos pontos 7 (inverno $26,5^{\circ} \mathrm{C}$ ), 8 (outono $30,4^{\circ} \mathrm{C}$ e primavera $35,9^{\circ} \mathrm{C}$ ) e 16 (verão $32,7^{\circ} \mathrm{C}$ ). Como ocorrido no período matutino, a diminuição térmica está relacionada à presença de vegetação nos pontos 7 e 8 , pertencentes à mesma via, juntamente com um curso d'água e, no ponto 16, relaciona-se a existência de uma praça arborizada no entorno do ponto. Segundo Duarte (1995), muitas são as funções da vegetação em espaços urbanos, principalmente em casos de cidades como Cuiabá, de clima rigoroso, com altas temperaturas ao longo de todo o ano, a amenidade climática se constitui como um dos principais benefícios que a vegetação urbana pode promover para a cidade.

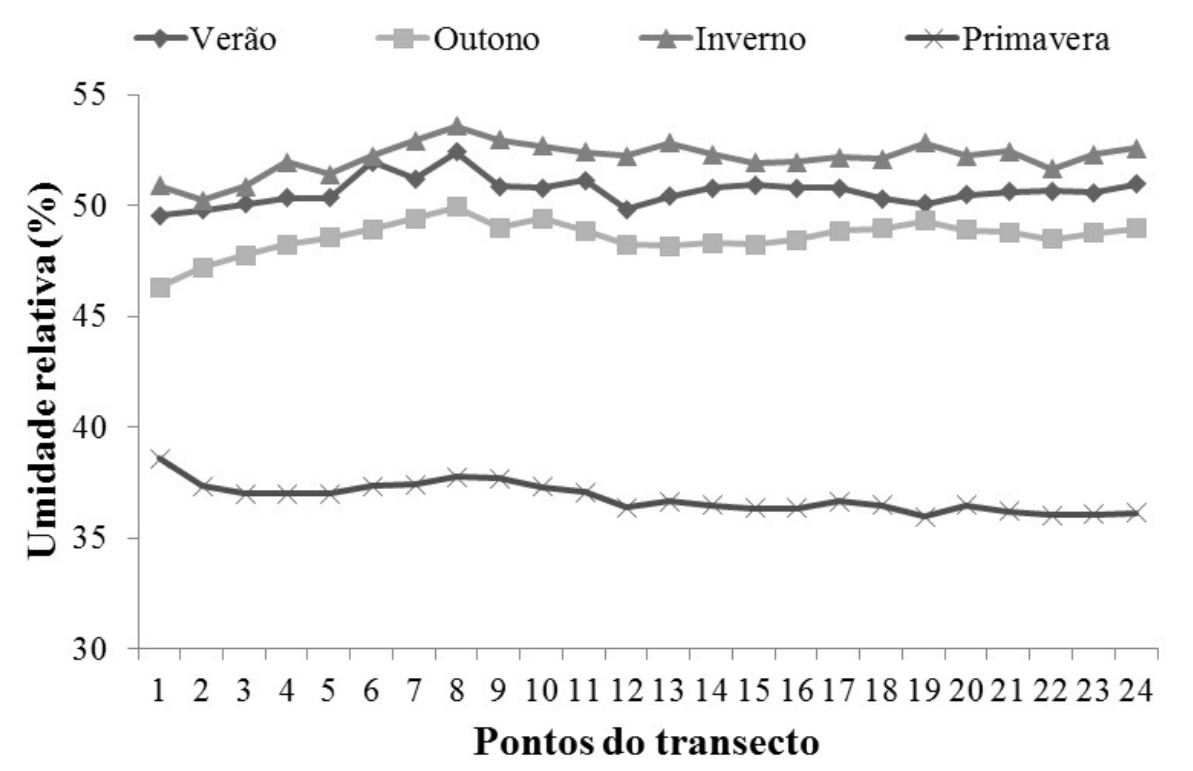

Figura 6 - Valores das umidades relativas nos 24 pontos do transecto nas quatro estações do ano (verão, outono, inverno e primavera) período vespertino (14h). 
Com relação às umidades relativas médias do ar (Figura 6), as maiores foram aferidas nos pontos 1 (primavera 38,5\%), 8 (verão 52,4\% e inverno 53,5\%) e 19 (outono 49,3\%), e as menores foram encontradas nos pontos, 1 (verão 49,4\% e outono 46,3\%), 2 (inverno 50,1\%) e 19 (primavera $35,9 \%$ ). O ponto 1 esteve entre as maiores e menores médios, sendo seu comportamento diferenciado em cada estação do ano. Nos pontos 8 e 9 há a presença de área verde e curso d'água, o que pode ter propiciado o aumento da umidade relativa média, já a queda da umidade relativa pode ser explicada nos pontos 1, 2 e 19, não devido a sua morfologia urbana, mas sim a atividade humana.

Há uma contradição entre as características tidas como amenizadoras do clima e responsáveis pelo aumento da umidade, pois no ponto 19 há proximidade com uma considerável área verde, no entanto a via na qual ele se encontra possui alto tráfego de veículos, sendo esse ultimo o fator determinante para a diminuição da umidade. Já o ponto 1 está posicionado em uma via de alto tráfego de veiculo e concentração de comércios, o que possibilitou que, no período vespertino da primavera, ele apresentasse as maiores médias de umidade relativa.

As maiores temperaturas médias do ar no período noturno nos pontos do transecto (figura 7), como na manhã e tarde, foram verificadas na estação da primavera com médias de aproximadamente $29^{\circ} \mathrm{C}$, seguida pelo verão $28^{\circ} \mathrm{C}$, outono $22^{\circ} \mathrm{C}$ e inverno $21^{\circ} \mathrm{C}$. Contrário ao que acontece com a temperatura, a umidade relativa da primavera foi a menor encontrada, com média aproximada de $56 \%$, nos pontos do transecto, o outono obteve a maior umidade relativa média $72 \% \%$, seguindo pelo inverno $65 \%$ e pelo verão $68 \%$ (figura 8 ).

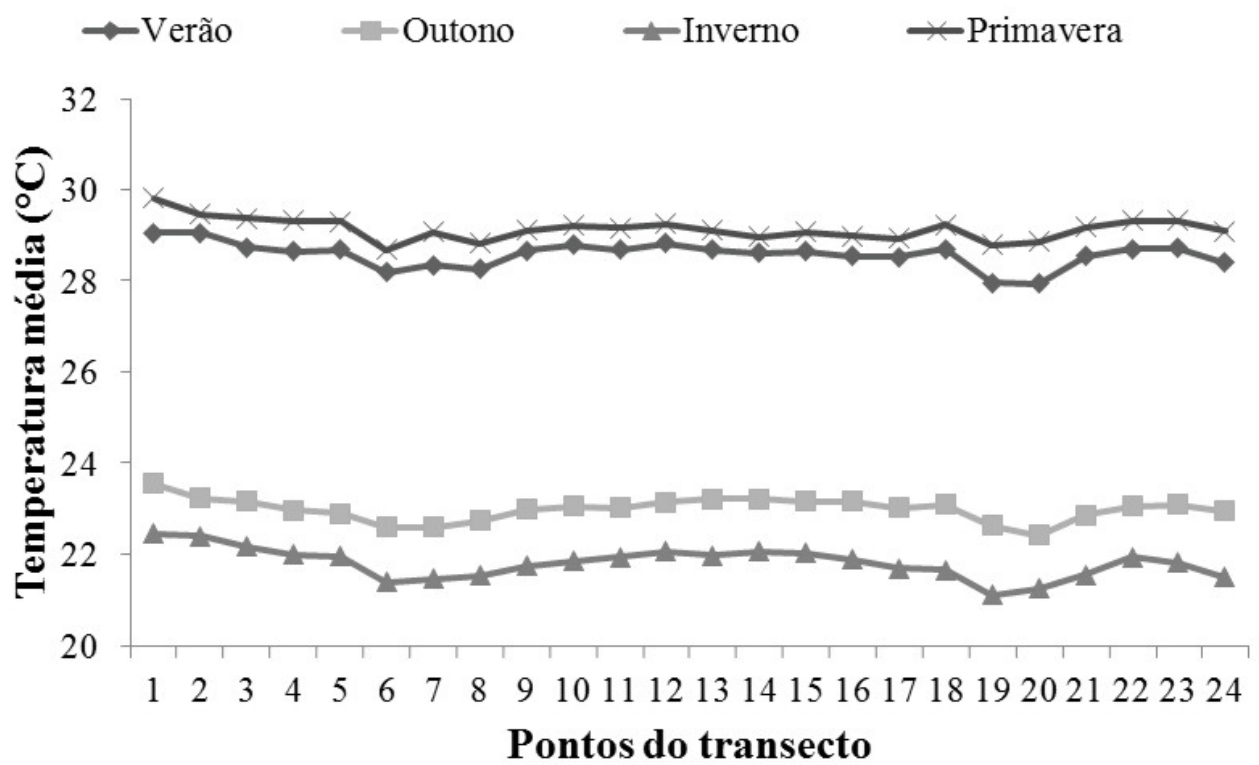

Figura 7 - Valores das temperaturas do ar nos 24 pontos do transecto nas quatro estações do ano (verão, outono, inverno e primavera) período noturno (20h)

No ponto 1 foram observadas as maiores temperaturas e menores umidades relativas médias do ar no período noturno em todas as estações do ano, isso devido a características citadas anteriormente, como fatores relativos à ação antrópica, uso e ocupação do solo e área construída, já que no período noturno há uma liberação do calor absorvido pela superfície edificada. As menores temperaturas médias foram observadas nos pontos 20 (verão $27,9^{\circ} \mathrm{C}$ e outono $22,4^{\circ} \mathrm{C}$ ), 19 (inverno $21,1^{\circ} \mathrm{C}$ ) e 6 (primavera $28,7^{\circ} \mathrm{C}$ ), pontos proximos a áreas verdes e cursos d'água em todos os casos, fato este responsável por amenizar as temperaturas, (Figura 7).

As maiores umidades relativas médias foram verificadas nos pontos 20 (verão $67,9 \%$, inverno $71,3 \%$ e primavera $57,5 \%$ ) e 19 (outono $74,4 \%$ ), região próxima ao rio Cuiabá e a uma extensa área verde, devido as correntes convectivas que sopram do rio para dentro do bairro o que não ocorre durante o dia, (Figura 8). 


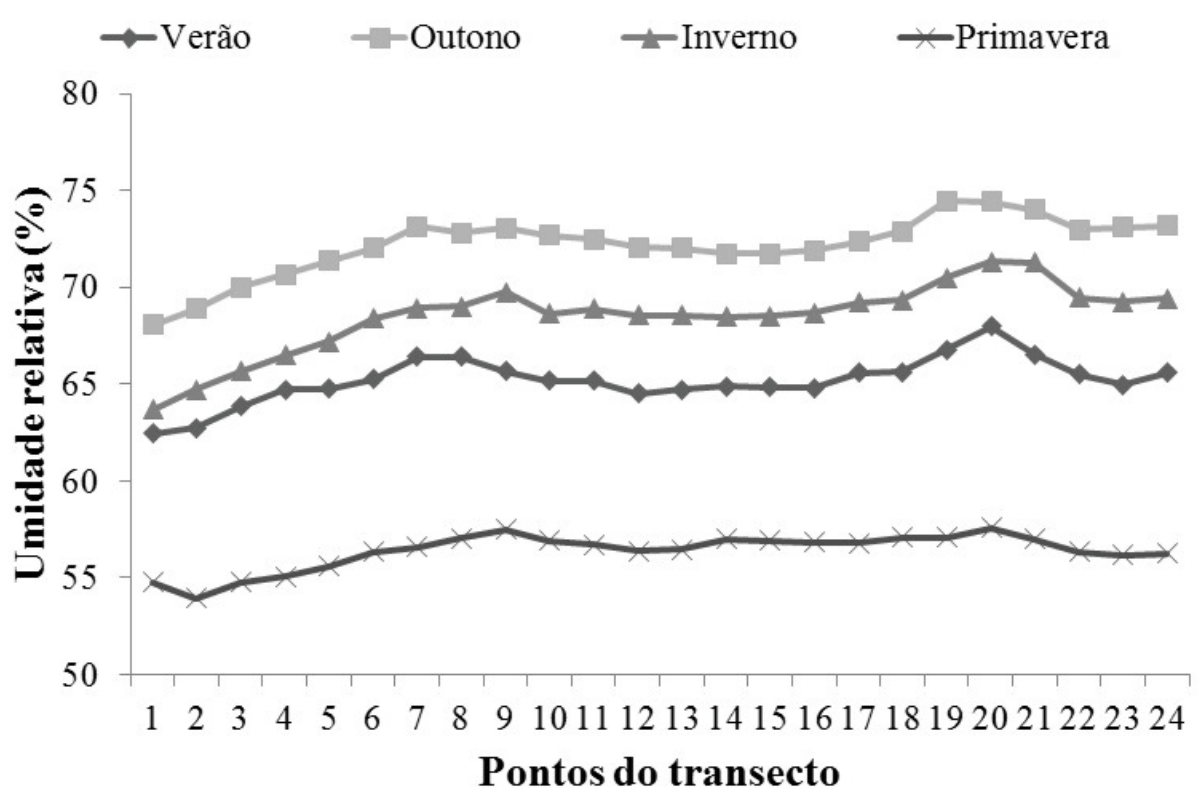

Figura 8 - Valores das umidades relativas nos 24 pontos do transecto nas quatro estações do ano (verão, outono, inverno e primavera) período noturno (20h)

\section{Análise estatística de agrupamento}

Para a análise estatística dos dados foi elaborado um dendrograma de similaridade (figura 9), utilizando a média anual, englobando todas as estações (verão, outono, inverno e primavera). A análise hierárquica de agrupamantos foi desenvolvida através do programa estatístico PASW Statistics 18. Os pontos foram reunidos em 7 grupos de modo que todos os pontos pudessem ficar correlacionados. A $\backslash$ figura 9 ilustra os grupos e os pontos pertencentes a cada grupo.

No grupo 1 os pontos 15, 16, 17, 13 e 14 formam um único agrupamento. O comportamento do grupo em relação à umidade relativa e a temperatura média do ar são semelhantes, pois os pontos estão localizados em seqüência e apresentarem características similares de uso e ocupação do solo e área construída.

O grupo 2, formado pelos pontos 10,12, 11 e 18 é composto por 3 subgrupos, um formado pelos pontos 10 e 12, outro somente pelo 11 e outro englobando o ponto 18 . Os pontos $10,11 \mathrm{e}$ 12 estão localizados na mesma via enquanto o ponto 18 está localizado em uma via paralela com aproximadamente $500 \mathrm{~m}$ de distância. A semelhança entre os pontos está ligada ao tipo de uso e ocupação do solo existente no local predominantemente comercial.

O grupo 3, formado pelos pontos 3, 4 e 5 é composto por 2 subgrupos, um englobando os pontos 3 e 4 e outro formado pelo ponto 5 . Os pontos estão localizados na mesma rua caracterizada por um alto tráfego de veículos e uma taxa de ocupação mediana.

O grupo 4, formado pelos pontos 7, 8, 6 e 9 é composto por 3 subgrupos, um formado pelos pontos 7 e 8 , outro pelo ponto 6 e outro englobando o ponto 9. Os pontos estão localizados em seqüência, próximos a áreas verdes, pouca área construída. Somente nas próximidades dos pontos 8 e 9 observa-se a existência de um prédio residencial multifamiliar.

O grupo 5, formado pelos pontos 21, 22, 23 e 24 é composto por 2 subgrupos, um englobando os pontos 21 e 22 e outro os pontos 23 e 24 . Os pontos estão localizados na mesma situação de uso e ocupação e taxa de área construída.

No grupo 6, os pontos 19 e 20 formam um unico agrupamento. Os pontos estão localizados em áreas de conflito de transito e estão na mesma via, com as mesmas características da malha urbana, uso e ocupação do solo e área construida. 

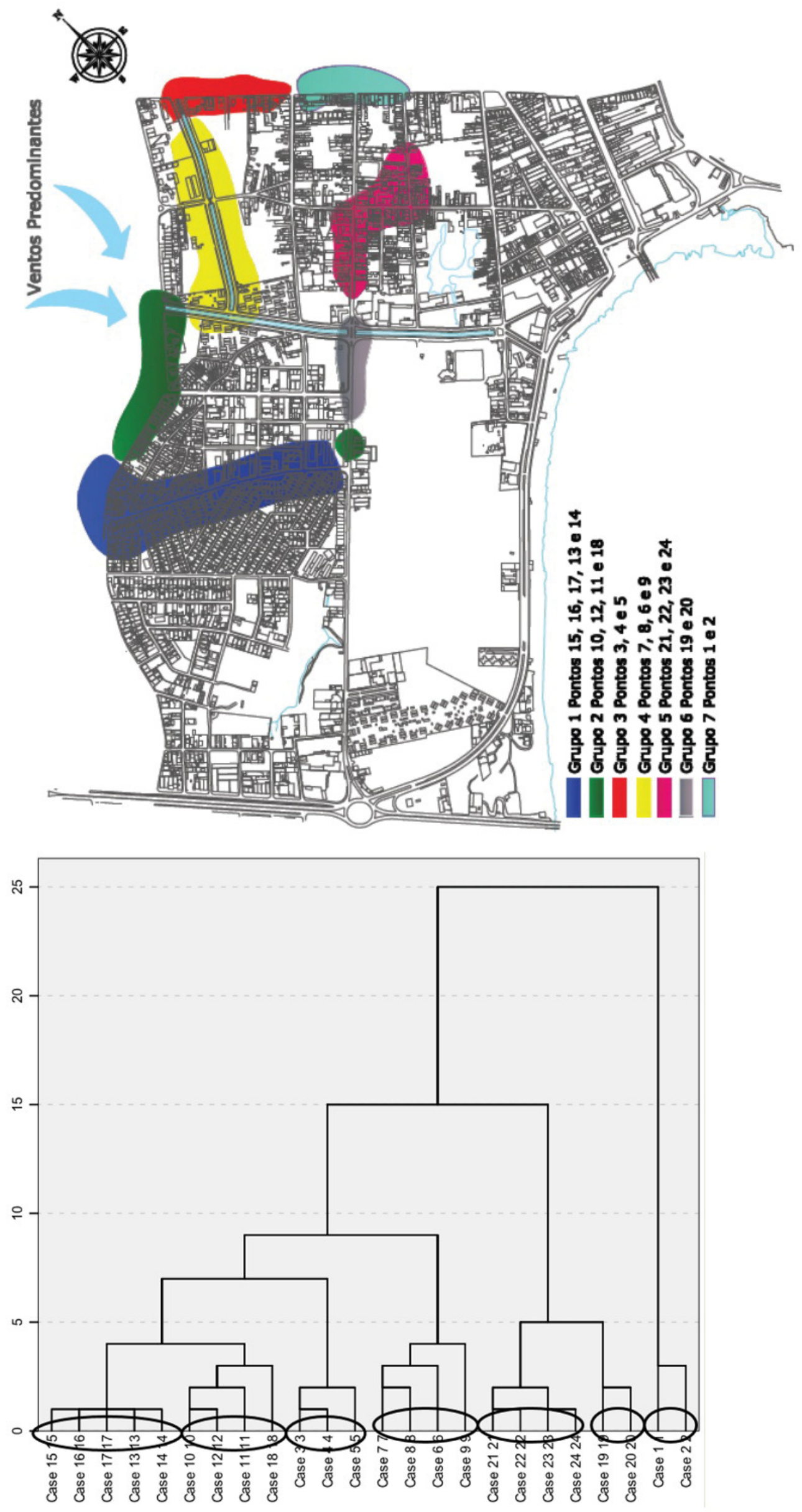

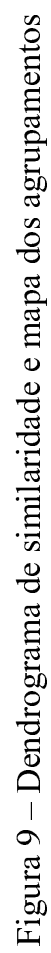


No grupo 7, os pontos 1, 2 formam um unico agrupamento. Os pontos situam-se em uma via de tráfego intenso e de uso e ocupação do solo predominantemente comercial, as maiores temperaturas foram notadas nesses pontos.

Com a análise global utilizando os dados de todas as estações do ano (verão, outono, inverno e primavera), observa-se que os pontos de um modo geral se agruparam segundo a sua localização dentro da malha urbana, constatando assim que as características de uso e ocupação, área construída e área verde são o principal contribuinte para a definição do microclima urbano. Como exceção tem se o grupo 2 que teve como seu componente o ponto 18 que está distante dos outros pontos do grupo, no entanto apresentou caracteristicas higotérmicas semelhantes aos demais pontos do grupo.

Estudos realizados por Zhao et. al. (2011) na cidade de Pequim em onze locais distintos, representantes de diferentes morfologias urbanas, são usados para simular efeitos de ilha de calor urbano e explorar a relação entre os indicadores de planejamento urbano e os indicadores de clima, como a temperatura máxima diária e a temperatura mínima. Os resultados indicam que na mesoescala os indicadores de planejamento urbano podem explicar a maioria das diferenças de clima urbano entre os locais. Por exemplo, a taxa da área de cobertura verde pode explicar de 94,47\% a 98,57\% da variância da temperatura máxima diária de superfície, a razão da cobertura verde e altura do edifício podem explicar 98,94\% a 99,12\% da variação de temperatura superficial mínima diária, e no solo a razão da área de taxa de cobertura verde e densidade de construção juntos podem explicar de $99,49 \%$ a 99,69\% da variância para o tempo de pico da temperatura da superfície. Aspecto que também é abordado e discutido nos trabalhos de Georgi e Dimitriou (2010), Fioretti et. al. (2010) e Alexandri e Jones (2008). Além disso, a taxa de cobertura verde é identificada como o indicador mais importante de planejamento urbano que afetam termicamente o ambiente citadino.

\section{CONSIDERAÇÕES FINAIS}

A configuração urbana, assim como as ações antrópicas, influencia diretamente o comportamento térmico e higrométrico local. As maiores temperaturas médias e menores umidade relativas médias do ar foram encontradas nos locais de alto trânsito de veículos, com maior concentração de comércios e alta densidade de área construída. Os pontos onde se constatou as menores temperaturas médias e maiores umidades relativas médias do ar encontram-se próximos a áreas verdes, cursos d'água, e regiões de pouca área construída e reduzido tráfego de veículos.

A análise de agrupamento comprovou a semelhança entre as áreas que possuem morfologia urbana semelhante, juntamente com elementos da paisagem tais como vegetação e presença de água. Mas também foi observada a ação antrópica como um fator explicito das alterações climáticas.

A influência da proximidade com o rio Cuiabá foi significativa nas temperaturas noturnas. As brisas por convecção ocorrente no período noturno foram importantes para a diminuição das temperaturas médias do ar.

Durante a pesquisa de campo, constatou-se que o bairro Porto apresenta inúmeros vazios urbanos, provavelmente decorrentes da especulação imobiliária, assim também como áreas verdes que representam $37,15 \%$ da área total do bairro.

A configuração urbana e os processos de desenvolvimento das cidades não dependem apenas do modo e distribuição da malha urbana, mas sim do uso e ocupação do solo, da distribuição das áreas verdes e principalmente do funcionamento da vida citadina, como foi observado no estudo realizado na cidade de Cuiabá no bairro do Porto.

\section{REFERÊNCIA BIBLIOGRÁFICA}

ALEXANDRI, E. JONES P. Temperature decreases in an urban canyon due to green walls and green roofs in diverse climates. Building and Environment, v 43, 2008. 
BRASIL. Ministério da Agricultura, Pecuária e Abastecimento. Instituto Nacional de Meteorologia - INMET. INMET no Distrito Federal. Climatologia. 2003. Disponível em: $<$ http://www.inmet.gov.br/climatologia $>$. Acesso em: 13/09/2008.

CORBELlA, O. D.; MAGALHÃES, M. A. A. A. Conceptual differences between the bioclimatic urbanism for Europe and for the tropical humid climate. Renewable Energy, v.33, 2008.

DUARTE, D. H. S. O Clima como Parâmetro de Projeto para a Região de Cuiabá. Dissertação (Mestrado em Arquitetura e Urbanismo)- Departamento de Arquitetura e Urbanismo, Universidade Federal de São Carlos, São Carlos, 1995.

FIORETTI, R. PALLA, A. LANZA, L. G. PRINCIPI P. Green roof energy and water related performance in the Mediterranean climate. Building and Environment, v45, 2010.

FRANCO, F. M. Configuração Urbana e sua Interferência no Microclima Local: Estudo de Caso no Bairro do Porto em Cuiabá-MT. Dissertação (Mestrado em Física e Meio Ambiente), Instituto de Física, Universidade Federal de Mato Grosso, Cuiabá, 2010.

FRISCHENBRUDER, M. T. M., PELLEGRINO P. Using greenways to reclaim nature in Brazilian cities. Landscape and Urban Planning, v.76, p 67-78, 2006.

GEORGI, J. N. DIMITRIOU, D. The contribution of urban green spaces to the improvement of environment in cities: case study of Chania, Greece. Building and Environment, v45, 2010.

GIVONI, B. Urban Design in Different Climates. Geneva: WMO Technical Document, n.346, 1989.

KATZSCHNER, L. Urban climate studies as tools for urban planning and architecture. In: IV Encontro Nacional de Conforto no Ambiente Construído, Salvador. Anais... Salvador: FAUUFBA/LACAM-ANTAC, p.49-58, 1997.

LEÃO, E. B. Carta Bioclimática de Cuiabá. Dissertação. (Mestrado em Física e Meio Ambiente) - Departamento de Física, Universidade Federal de Mato Grosso, Cuiabá, 2007.

OKE, T. R. Boundary layer Climates. New York Metheun \& Co. Ltd, 1987.

OLIVEIRA, P. M. P. Metodologia de desenho urbano considerando os atributos bioclimatizantes da forma urbana e permitindo controle do conforto ambiental, do consumo energético e dos impactos ambientais. Brasília: Universidade de Brasília, 1993.

OLGYAY, V. Design with Climate. Bioclimatic Approach to Architectural Regionalism. 4th ed. Princeton, New Jersey, U. S. A.: Princeton University Press, 1963.

SAILOR, D. J. Mitigation Of Urban Heat Islands - Recent Progress And Future Prospects. 6th Symposium on the Urban Environment and Forum on Managing our Physical and Natural Resources, 31 January, 2006.

SIQUEIRA, E. M.; et al. Cuiabá: de vila a metrópole nascente. Textos vários autores. $2^{\circ}$ Ed. Cuiabá: Editora Entrelinhas, 2007.

TSIROS, I. X. Assessment and energy implications of street air temperature cooling by shade trees in Athens (Greece) under extremely hot weather conditions. Renewable Energy journal, v35, 2010.

XU, J. WEI, Q. HUANG, X. ZHU, X. LI, G. Evaluation of human thermal comfort near urban waterbody during summer. Building and Environment v.45, 2010.

ZHAO, C. FU, G. LIU, X. FU, F. Urban planning indicators, morphology and climate indicators: A case study for a north-south transect of Beijing, China. Building and Environment, v.46, 2011.

Trabalho enviado em novembro de 2011

Trabalho aceito em dezembro de 2011 